\title{
A rare case of dual origin of the left vertebral artery without convergence
}

\author{
K. Watanabe, T. Saga, J. Iwanaga, Y. Tabira, K. Yamaki \\ Department of Anatomy, Kurume University School of Medicine, Fukuoka, Japan
}

[Received: 25 March 2015; Accepted: 15 April 2015]

A case of dual origin of the left vertebral artery was encountered in a dissection course for medical students in 2014. Two vertebral arteries were observed on the left side. One arose from the aortic arch between the origin of the left common carotid artery and the left subclavian artery, entered the transverse foramen of the 4 th cervical vertebra, and coursed upward into the transverse foramen. The other arose from the left subclavian artery as expected, divided into two branches anterior to the cervical vertebrae, and entered the transverse foramina of the 6th and 7 th cervical vertebrae. Both branches flowed into the anterior spinal artery. Moreover, as seen in other anomalies, 3 arterial fenestrations were observed in the cranial arteries. This case is extremely unique with respect to the following points: the 2 ipsilateral vertebral arteries did not combine to form 1 vertebral artery, the vertebral artery of subclavian artery origin entered the transverse foramen of the 7 th cervical vertebra, and 3 fenestrations were observed in the intracranial arteries. This is a very suggestive case for neurosurgeons and radiologists who perform treatments involving the vertebral artery. (Folia Morphol 2016; 75, 1: 136-142)

Key words: vertebral artery, duplication, fenestration, anterior spinal artery, transverse foramen, intersegmental artery, longitudinal anastomosis

\section{INTRODUCTION}

The vertebral artery has an important role in the posterior circulation of the brain. Accurate knowledge of the anatomy of the vertebral artery, including its variations, is extremely important for intracranial vascular treatment. An unusual entrance level of the transverse foramen is a well-known anatomical variation. An abnormal origin of the vertebral artery is also sometimes observed. Some anatomical variations induce symptoms such as headache or vertigo and require careful differential diagnosis from arterial dissection, stenosis, occlusion, or other vascular disease. A dual origin of the vertebral artery has been reported in approximately 36 cases. In most of these cases, 2 arteries of dual origin united to form 1 vertebral artery at various levels [9]. In 1 case, however, the 2 arteries did not unite and flowed into different arteries [13]. We herein report the detailed findings of another case of this extremely rare anomaly, consider the embryological causes, and review previously reported cases.

\section{MATERIALS AND METHODS}

A case of dual origin of the left vertebral artery was encountered in an anatomical dissection course of our medical school in 2014. The case involved a 95-year-old woman with a slight, small build who died of natural causes. No signs of structural disorders, surgical scars, or other anomalies were found on or in her body. 


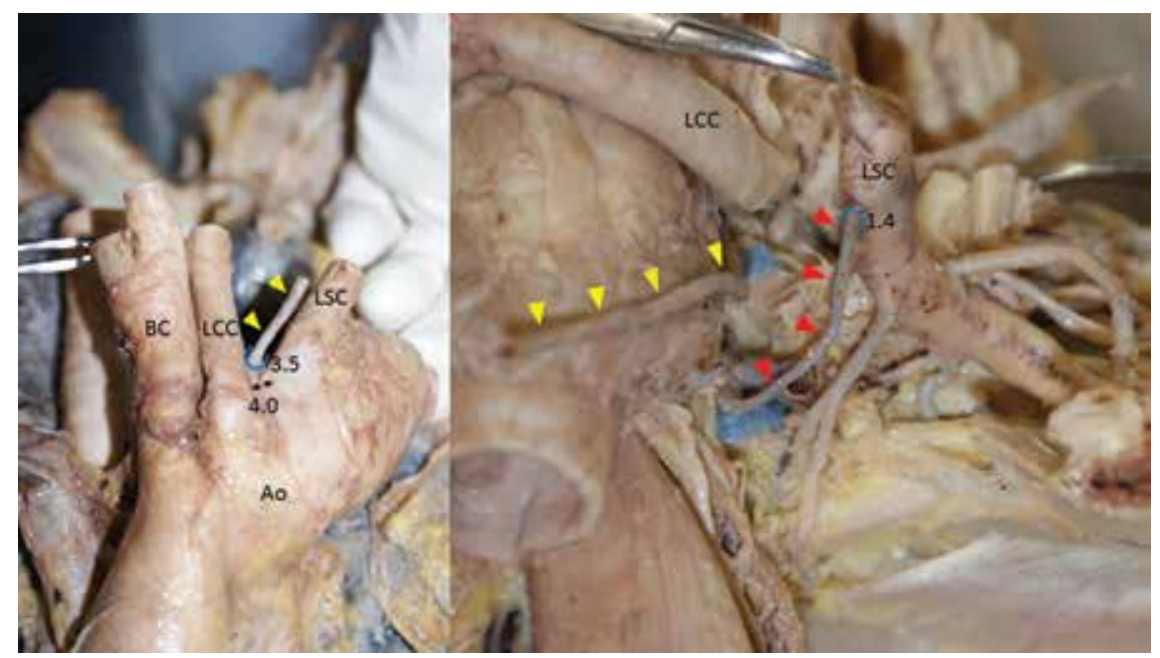

Figure 1. Aortic arch and left subclavian artery dissection findings. Distance between the origin of the left common carotid artery (LCC) and left subclavian artery (LSC): $4.0 \mathrm{~mm}$. Diameter of the origin of the left vertebral artery of aortic arch origin (yellow arrowhead): $3.5 \mathrm{~mm}$. Diameter of the origin of the left vertebral artery of LSC origin (red arrowhead): $1.4 \mathrm{~mm} ; \mathrm{Ao}$ - aortic arch; BC — brachiocephalic artery.

\section{RESULTS}

A dual origin of the left vertebral artery was observed. One artery arose from the aortic arch between the origin of the left common carotid artery and left subclavian artery; its diameter was $3.5 \mathrm{~mm}$. The other arose from the left subclavian artery as expected; its diameter was $1.4 \mathrm{~mm}$ and the distance from the origin of the left subclavian artery was $42 \mathrm{~mm}$ (Fig. 1). The former entered the transverse foramen of the 4th cervical vertebra (the diameter of the artery at this point was $3.0 \mathrm{~mm}$ ), ascended in the transverse foramen, joined the right vertebral artery, and became the basilar artery. The latter bifurcated into 2 branches just before entering the transverse foramen; the 2 branches entered the transverse foramina of the 6 th and 7th cervical vertebrae (the diameters of the 2 arteries at this point were $1.1 \mathrm{~mm}$ and $0.8 \mathrm{~mm}$, respectively) (Figs. 2, 3). These 2 branches did not ascend in the transverse foramina, but ran transversally along the anterior roots of the spine as radiculomedullary arteries and flowed into the anterior spinal artery. The anterior spinal artery flowed only into the left vertebral artery, which differs from the typical course involving the point just before the confluence of the bilateral vertebral arteries. The right vertebral artery arose from the right subclavian artery as expected and the distance between origin of the right subclavian artery and the right vertebral artery was $53.0 \mathrm{~mm}$. The artery entered the transverse foramen of the 5th cervical vertebra; its diameter was $3.6 \mathrm{~mm}$ (Fig. 3).

Other abnormalities were also observed, including 3 fenestrations in the anterior spinal, basilar, and left anterior cerebral arteries. Two hypoplastic anterior communicating arteries were present. The left posterior cerebral artery arising from the basilar artery (known as P1) was hypoplastic (Fig. 4).

\section{DISCUSSION}

A dual origin of the left vertebral artery is an extremely rare variation. Excluding the cases reported in the 19th century, only 26 cases were reported until 1999 [9]. To the best of our knowledge, nine additional cases have been reported since then (Table 1) [6, 8, $12,13,16-19]$. Thus, we consider that 36 cases have been reported (26 cases reviewed by Komiyama and 10 cases reported since 1999, including our case). These 36 cases can be summarised as follows. Eighteen cases occurred in males and 14 occurred in females; the sex was not described in 4 cases. Fourteen cases involved in the right side, 19 involved the left side, and 3 were bilateral. Three types of dual origins of the right vertebral artery were described: both from the right subclavian artery in 15 cases, 1 from the brachiocephalic artery and another from the right subclavian artery in 1 case, and 1 case from the aorta and another from the subclavian artery in 1 case. Three types of dual origins of the left vertebral artery were also described: 1 from the aortic arch and another from the left subclavian artery in 20 cases, both from the left subclavian artery in 1 case [6], and 1 case from the aortic arch and another from the thyrovertebral trunk which arose from the aorta in 1 case $[7,9]$. The present case involved the most typical dual origin of the left vertebral artery (aortic arch and left subclavian artery). 


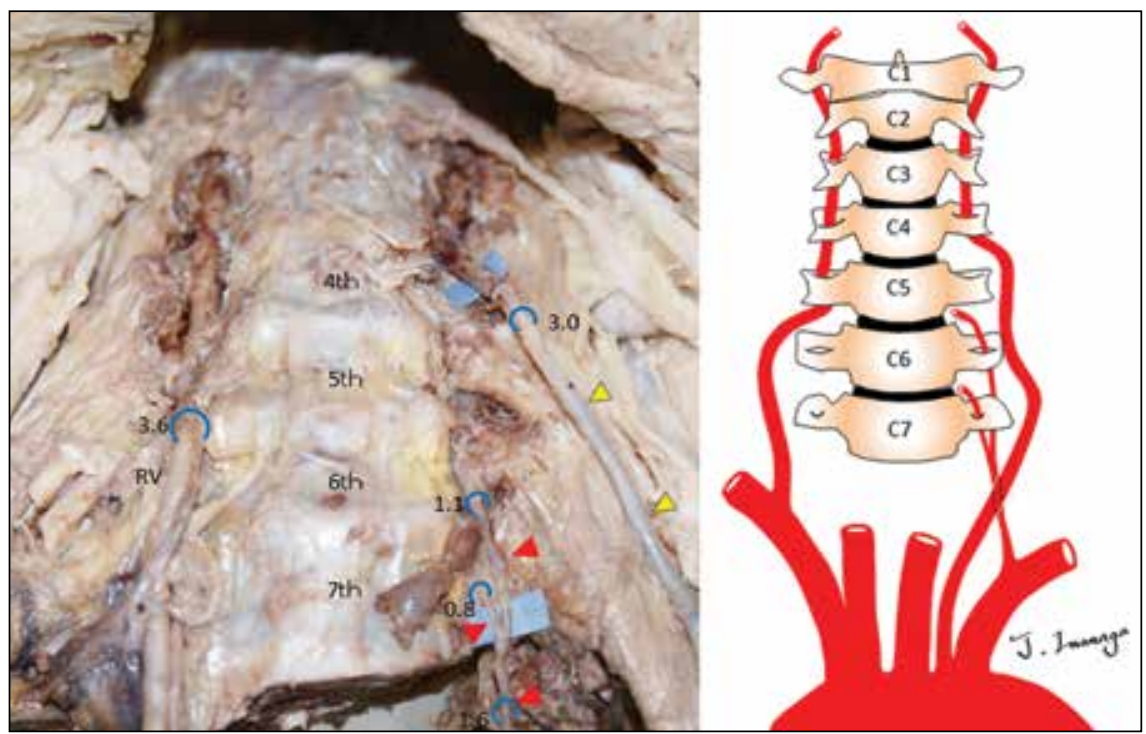

Figure 2. Neck dissection findings. Transverse foramina of the cervical vertebrae were opened by removing the anterior tubercles. Diameter of entrance point of right vertebral artery (RV) into the transverse foramen: $3.6 \mathrm{~mm}$. Diameter of entrance point of left vertebral artery of aortic arch origin into the transverse foramen: $3.0 \mathrm{~mm}$. Diameter of entrance point of branches of left vertebral artery of left subclavian origin into the transverse foramen: $1.1 \mathrm{~mm}$ (6th cervical vertebra) and $0.8 \mathrm{~mm}$ (7th cervical vertebra).

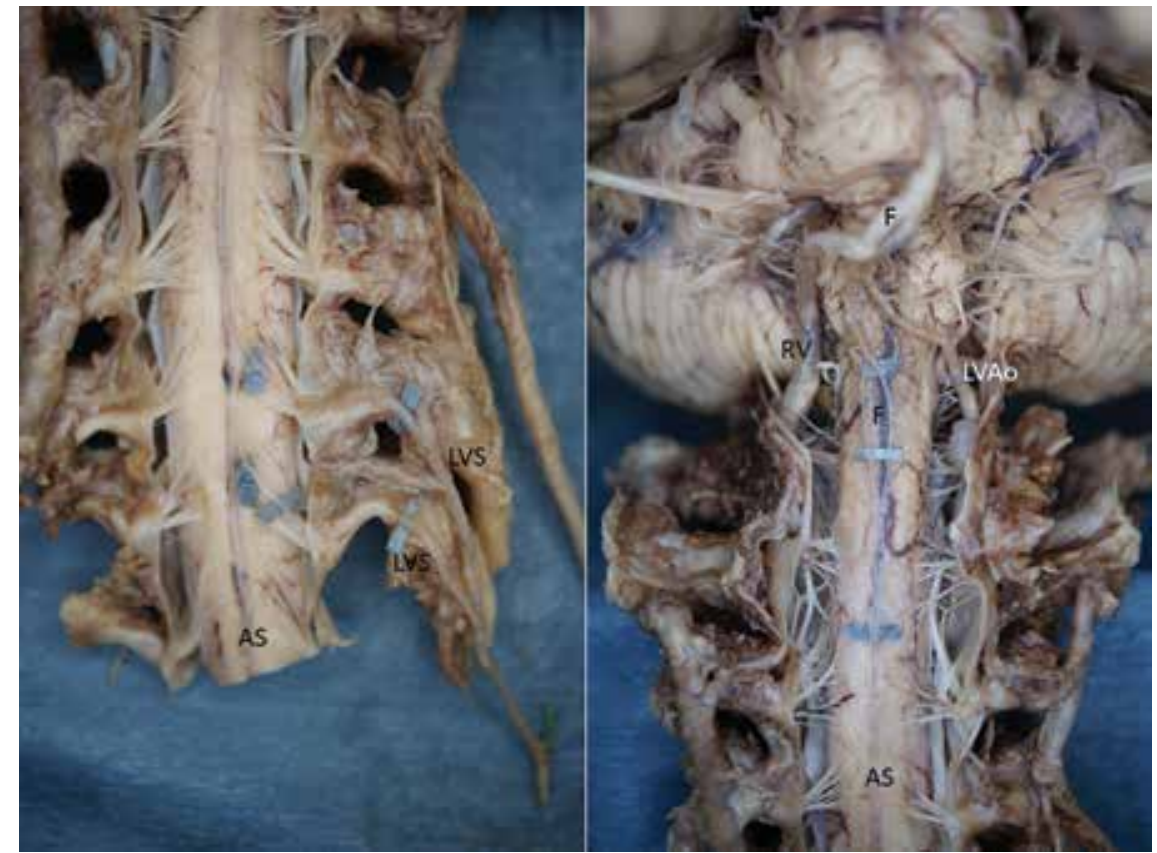

Figure 3. Spinal cord dissection findings. The 2 left vertebral arteries of subclavian artery origin did not ascend to the transverse foramina, but became radiculomedullary arteries and joined the anterior spinal artery (AS). A fenestration in the AS was also observed; $F$ - fenestration; LVAo - left vertebral artery of aortic arch origin; LVS — left vertebral artery of subclavian artery origin; RV — right vertebral artery.

The cause of this anomaly can be explained by the following embryological theory. In normal human development, the branchial arches develop at the 4th week, and 6 paired aortic arches that connect the aortic sac and bilateral dorsal aortas develop and supply the blood to each branchial arch. The first and second of these paired aortic arches regress and disappear. The 3rd aortic arch becomes the common and internal carotid arteries, and the left 4th aortic arch becomes the aortic arch (Fig. 5) [11]. The dorsal aorta then 


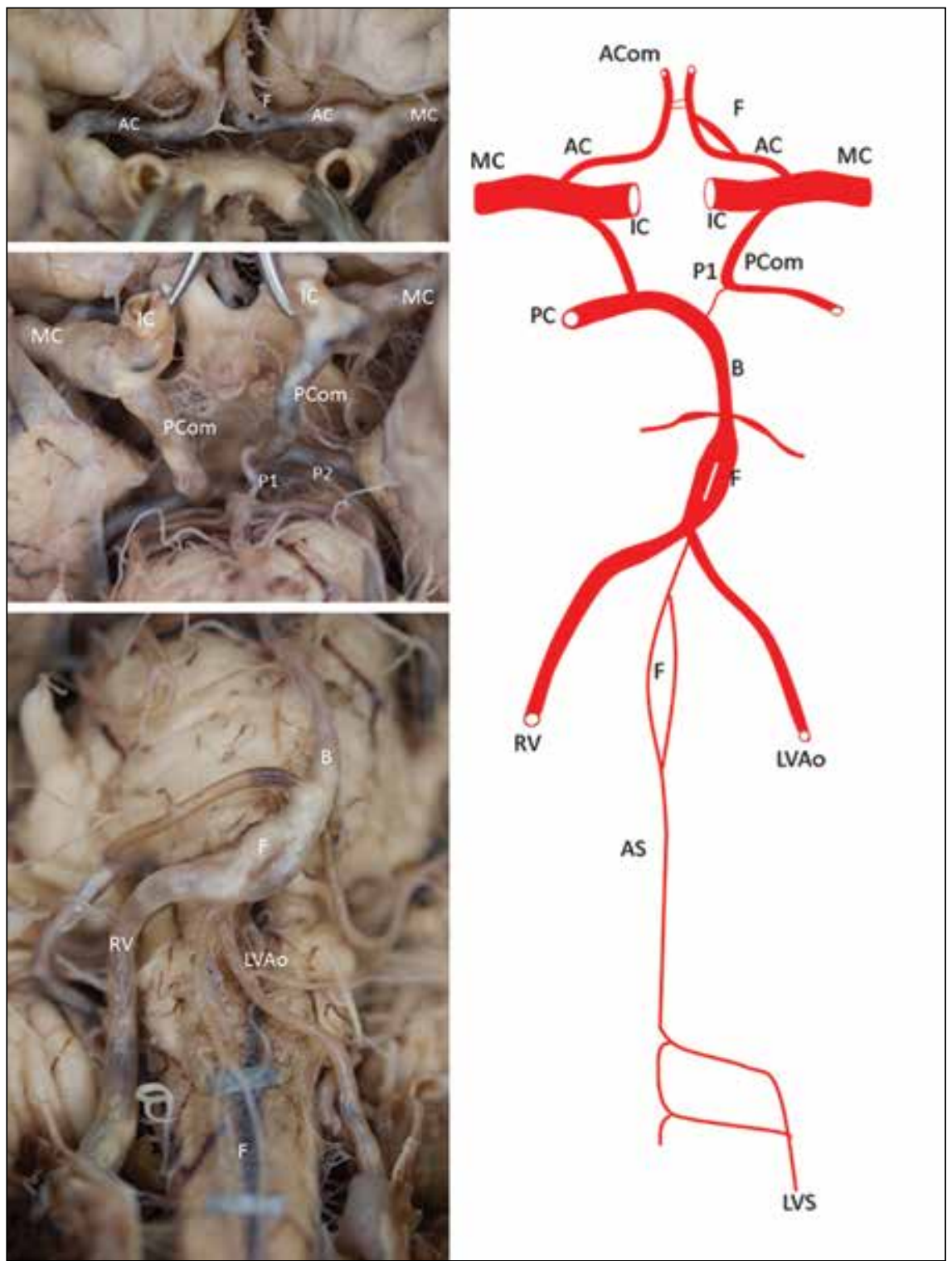

Figure 4. Brain dissection findings. The anterior spinal artery (AS) flowed only into the left vertebral artery at the point just before the junction with the right vertebral artery (RV). A fenestration (F) was observed in the basilar artery (B). At the cerebral arterial circle, the origin of the left posterior cerebral artery (P1) was hypoplastic and narrower than the right side. A fenestration was observed in the left anterior cerebral artery. The anterior communicating artery was extremely hypoplastic, and a few funicular structures were observed; $A C$ - anterior cerebral artery; IC — internal carotid artery; LVAo — left vertebral artery of aortic arch origin; MC — middle cerebral artery; PC — posterior communicating artery; $\mathrm{P} 1$ - the part of the posterior cerebral artery from the termination of the basilar artery to the posterior communicating artery; P2 - the part of the posterior cerebral artery peripheral to the posterior communicating artery; LVS — left vertebral artery od subclavian artery origin; ACom — anterior communicating artery; PCom — posterior communicating artery.

gives rise to three kinds of branches: the dorsal, lateral, and ventral branches. Approximately 30 paired dorsal intersegmental arteries arise, creating 3 main longitudinal anastomoses: precostal, postcostal, and post-transverse anastomoses with regression of most of the parts. The precostal anastomosis becomes the thyrocervical trunk in the neck and the costocervical trunk in the upper thoracic region. The postcostal anastomosis (1st to 6 th dorsal intersegmental artery) becomes the vertebral artery in the neck. Finally, the post-transverse anastomosis becomes the deep cervical artery. These longitudinal anastomoses are connected to the 7th intersegmental artery, which becomes the subclavian artery (Fig. 5) $[2,14,15]$. In our case, one vertebral artery arose from the aortic arch between the left common carotid artery and left subclavian artery, and the other vertebral artery arose normally from the left subclavian artery. The left vertebral artery of aortic origin was presumed to be the remnant of the 4 th intersegmental artery, which 
Table 1. Newly reported cases of dual origin of the vertebral artery

\begin{tabular}{|c|c|c|c|c|c|c|c|c|c|c|}
\hline $\begin{array}{l}\text { Case } \\
\text { No. }\end{array}$ & $\begin{array}{l}\text { Author } \\
\text { (Year) }\end{array}$ & Age/Sex & Laterality & Medial leg & Entrance & Lateral leg & Entrance & $\begin{array}{l}\text { Union } \\
\text { level }\end{array}$ & $\begin{array}{l}\text { Disease/ } \\
\text { Symptom }\end{array}$ & Remarks \\
\hline \multirow[t]{2}{*}{1} & $\begin{array}{l}\text { lonete } \\
\text { (2006) }\end{array}$ & 83/Male & Bilateral & RSA & C4 & RSA & C7 & $\mathrm{C} 4 / \mathrm{C} 5$ & $\begin{array}{l}\text { Mild cognitive } \\
\text { impairment }\end{array}$ & \\
\hline & & & & LSA & C5 & LSA & $\mathrm{C7}$ & $\mathrm{C} 5 / \mathrm{C} 6$ & & \\
\hline 2 & $\begin{array}{l}\text { Thomas } \\
(2008)\end{array}$ & 49/Female & Right & RSA & C6 & RSA & C6 & & $\begin{array}{l}\text { Unruptured } \\
\text { midbasilar } \\
\text { aneurysm }\end{array}$ & $\begin{array}{l}\text { Medial leg } \\
\text { and lateral } \\
\text { leg united } \\
\text { and entered } \\
\text { the C6 } \\
\text { transverse } \\
\text { foramen }\end{array}$ \\
\hline \multirow[t]{2}{*}{3} & $\begin{array}{l}\text { Mordasisni } \\
\text { (2008) }\end{array}$ & 48/Male & Bilateral & RSA & C4 & RSA & C7 & $\mathrm{C} 4 / \mathrm{C5}$ & $\begin{array}{l}\text { Middle cer- } \\
\text { ebral artery } \\
\text { stroke }\end{array}$ & \\
\hline & & & & Aortic arch & C4 & LSA & C7 & $\mathrm{C} 4 / \mathrm{C} 5$ & & \\
\hline 4 & $\begin{array}{l}\text { Kim } \\
(2009)\end{array}$ & 42/Female & Left & Aortic arch & Unknown & LSA & Unknown & Unknown & $\begin{array}{l}\text { Atrioven- } \\
\text { tricular fistula } \\
\text { between the } \\
\text { right vertebral } \\
\mathrm{A} \text { and V }\end{array}$ & $\begin{array}{l}\text { Fenestration } \\
\text { of left verte- } \\
\text { bral artery }\end{array}$ \\
\hline 5 & $\begin{array}{l}\text { Tobin } \\
(2010)\end{array}$ & 48/Male & Left & Aortic arch & Unknown & LSA & Unknown & C6 & & \\
\hline 6 & $\begin{array}{l}\text { Nakamura } \\
\text { (2012) }\end{array}$ & $\begin{array}{l}\text { No } \\
\text { description }\end{array}$ & Left & Aortic arch & C3 & LSA & C5 & $\begin{array}{l}\text { Non- } \\
\text { union }\end{array}$ & $\begin{array}{l}\text { Cadaver } \\
\text { dissection }\end{array}$ & \\
\hline 7 & $\begin{array}{l}\text { Uchino } \\
\text { (2013) }\end{array}$ & 66/Male & Left & Aortic arch & Unknown & LSA & Unknown & C5 level & $\begin{array}{l}\text { Cerebral } \\
\text { infarction }\end{array}$ & \\
\hline 8 & $\begin{array}{l}\text { Uchino } \\
\text { (2013) }\end{array}$ & 76/Female & Right & RSA & Unknown & RSA & Unknown & C5 level & $\begin{array}{l}\text { Cerebral } \\
\text { aneurysm }\end{array}$ & \\
\hline \multirow[t]{2}{*}{9} & $\begin{array}{l}\text { Rameshbabn } \\
\text { (2014) }\end{array}$ & 36/Male & Bilateral & RSA & C4 & RSA & C6 & $\mathrm{C} 4 / \mathrm{C5}$ & $\begin{array}{l}\text { History of } \\
\text { dizziness }\end{array}$ & \\
\hline & & & & Aortic arch & C5 & LSA & C6 & $\mathrm{C} 5 / \mathrm{C} 6$ & & \\
\hline 10 & Present case & 95/Female & Left & Aortic arch & C4 & LSA & $\mathrm{C} 6+\mathrm{C} 7$ & $\begin{array}{l}\text { Non- } \\
\text { union }\end{array}$ & None & \\
\hline
\end{tabular}

LSA — left subclavian artery; RSA — right subclavian artery

usually disappears. This remnant intersegmental artery developed into the vertebral artery and entered the 4th transverse foramen. The left vertebral artery of left subclavian origin was presumed to have been derived from the usual postcostal longitudinal anastomosis of the lower cervical intersegmental artery to the 7th intersegmental artery, which becomes the left subclavian artery (Fig. 5).

One extremely unique aspect of this case is that the 2 left vertebral arteries did not unite; one became the vertebral artery coursing upward in the transverse foramen, and the other coursed transversely and flowed into the anterior spinal artery after entering the transverse foramen. In the most cases of dual origin of the vertebral artery, the 2 vertebral arteries united at various heights and formed 1 vertebral artery [13]. To the best of our knowledge, no case similar to ours except that reported by Nakamura has been reported [13]. Embryologically, the anterior spinal artery also develops from the longitudinal anastomosis of the dorsal intersegmental arteries, which occurs at the anterior spinal cord. The bilateral intersegmental arteries anastomose with the upper and lower intersegmental arteries in the anterior paramedian region of the anterior spine and become 2 arteries that run perpendicularly. The 2 paramedian arteries then combine and become the anterior spinal artery. Most parts of the transversely running intersegmental arteries in the vertebral canal regress and disappear except the radiculomedullary artery, which flows into the anterior spinal artery from the vertebral artery [10]. We consider that in the present 


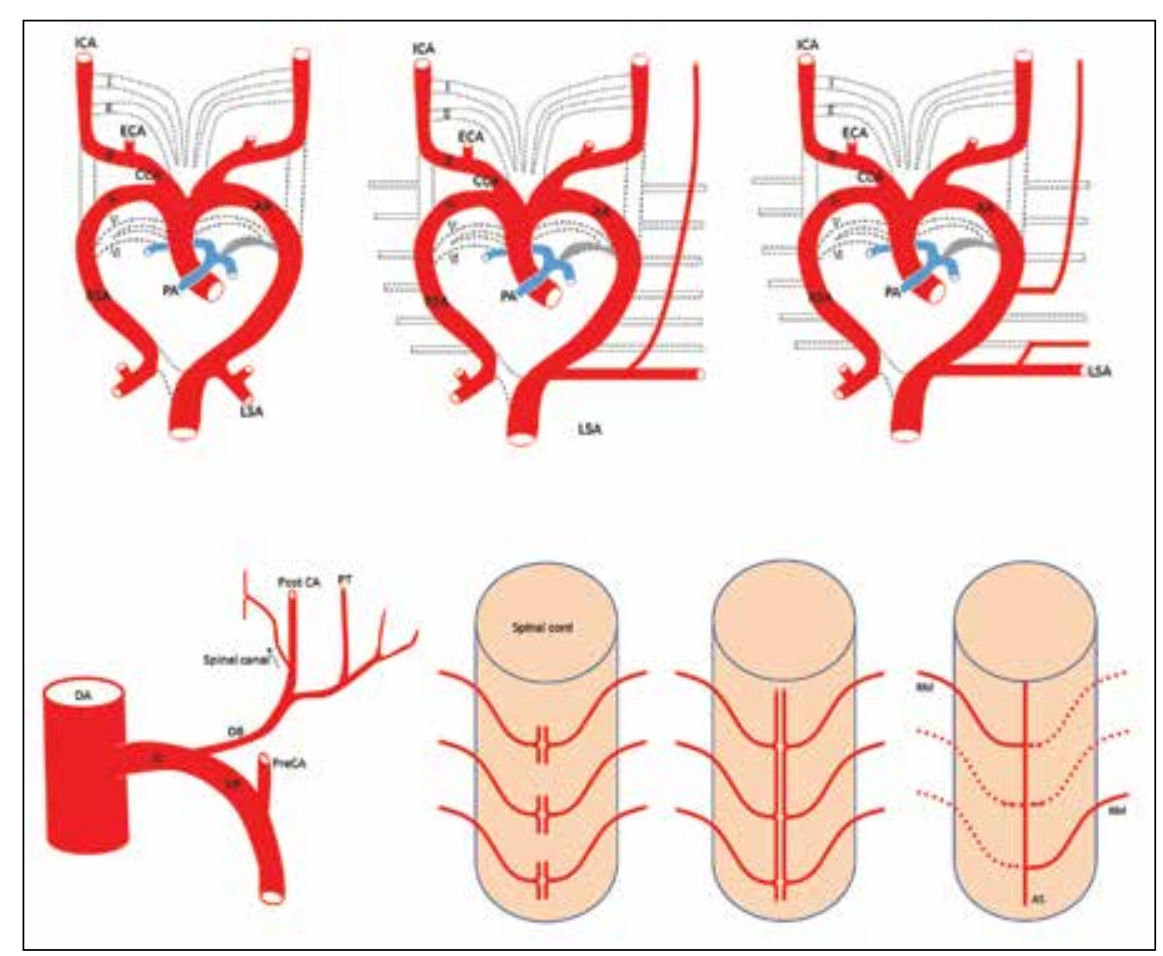

Figure 5. Consideration of the embryological development of this case. Upper left: Transformation of the aortic arches. The bilateral third aortic arch (AA) becomes the common carotid artery. The right and left fourth aortic arches become the root of the right subclavian artery and $A A$, respectively. The sixth AA bears the proximal part of the bilateral pulmonary arteries and ductus arteriosus. The first, second, and fifth AAs regress and disappear. Upper middle: Approximately 30 pairs of intersegmental arteries arise from the dorsal aorta and bilateral seventh intersegmental arteries, becoming the subclavian arteries. The first 6 intersegmental arteries usually regress, but a part of them forms a longitudinal anastomosis and becomes the vertebral artery, continuing to the subclavian artery. Upper right: Embryological consideration of the present case. The fourth left intersegmental artery remained without regression and formed the vertebral artery arising from the AA. The longitudinal anastomosis arising from the left subclavian artery then formed the vertebral artery arising from the left subclavian artery. Lower left: Detailed branching pattern of the intersegmental artery. The intersegmental artery has 2 branches: dorsal and ventral. The intersegmental artery connects to the upper and lower intersegmental arteries and forms 3 main longitudinal anastomoses: the precostal, postcostal, and post-transverse anastomosis. In the cervical region, the precostal anastomosis forms the thyrocervical trunk, the postcostal anastomosis forms the vertebral artery, and the post-transverse anastomosis forms the deep cervical artery. The dorsal branch has a further branch that courses to the spinal canal to form a longitudinal anastomosis of the anterior spinal artery. Lower right: From left to right, the bilateral intersegmental arteries extend in superior and inferior directions and form the 2 longitudinal anastomoses in the bilateral paramedian region of the anterior spinal root. The 2 paramedian arteries then combine to form the anterior spinal artery. Most of the intersegmental arteries disappear, but some arteries remain and become the radiculomedullary arteries. The white areas surrounded by the dotted line indicate the disappeared vessels, and the area containing slanted lines indicates the atrophic vessel; AS — anterior spinal artery; CCA — common carotid artery; DA — dorsal aorta; DB — dorsal branch of the intersegmental artery; ECA — external carotid artery; ICA — internal carotid artery; IS — intersegmental artery; LSA — left subclavian artery; PA — pulmonary artery; Post CA — postcostal anastomosis; PreCA — precostal anastomosis; PT — post-transverse anastomosis; RM — radiculomedullary artery; RSA — right subclavian artery; VB — ventral branch of the intersegmental artery. Roman numerals indicate the primitive aortic arches.

case, the radiculomedullary artery developed instead of regression of the postcostal longitudinal linkage in the transverse foramen (Fig. 5). According to this embryological theory, the fenestration in the anterior spinal artery can be explained as partial dysphagia of the bilateral paramedical arteries.

The vertebral artery of normal origin in this case divided into 2 branches that entered the 6th and 7th vertebral foramina. Entrance of a vertebral artery into the 7th transverse foramen is rare, and no clear embryological explanations have been proposed. The frequency of this anomaly reportedly ranges from
$0.3 \%$ to $8.8 \%$ of cases. In 1928 , Adachi and Hasebe [1] performed anatomical dissections and found 7 vertebral arteries entering the 7th transverse foramen in 86 (8.1\%) sides. In 1959, Daseler and Anson [4] reported that the vertebral artery entered the 7th vertebral foramen in $5.4 \%$ of cases: 41 specimens (16 on the right and 21 on the left) among 379 bodies. In 2006, Yamaki et al. [20] reported that the left vertebral artery arose from the subclavian artery and entered the 7 th transverse foramen in $8.8 \%$ of males and $7.5 \%$ of females. According to previous radiological reports, the frequency of the vertebral artery entering the 
C7 transverse foramen was $0.8 \%$ (4 in 500 sides) according to Bruneau et al. [3], 1.2\% (left) and 0.6\% (right) according to Uchino et al. [19], and $0.3 \%$ according to Hong et al. [5]. Although entrance of the vertebral artery into the 7th vertebral foramen is relatively rare, the left vertebral artery of normal origin in the present case split into 2 branches before entering the transverse foramen, and the 2 vessels then entered the 6 th and 7 th transverse foramina, respectively. This anomaly has not been described before.

\section{CONCLUSIONS}

We have reported the detailed anatomical findings of an extremely rare case of dual origin of the left vertebral artery. The 2 arteries did not coalesce into 1 vertebral artery. Moreover, this case was accompanied by multiple fenestrations and abnormal arteries running throughout the intracranial and intraspinal canal regions. This case is considered to be a very suggestive case for neurosurgeons and radiologists who perform treatments involving the vertebral artery.

\section{DISCLOSURE}

None of the authors has a financial interest in anything in this study and received any financial support to carry out the study. This study was performed in keeping with the requirements of the Declaration of Helsinki (64 ${ }^{\text {th }}$ WMA General Assembly, Fortaleza, Brazil, October 2013).

\section{REFERENCES}

1. Adachi B, Hasebe K (1928) Das arteriensystem der Japaner. Kaiserlich-japanische Universität zu Kyoto, in kommission bei Maruzen Company, Kyoto and Tokyo, pp. 152-153.

2. Arey LB, Gray CE (1935) Developmental anatomy. WB Saunders co, Philadelphia and London, pp. 350-360.

3. Bruneau M, Cornelius JF, Marneffe V, Triffaux M, George B (2006) Anatomical variations of the V2 segment of the vertebral artery. Neurosurgery, 59, ONS-20. doi: 10.1227/01. NEU.0000219931.64378.B5.

4. Daseler EH, Anson BJ (1959) Surgical anatomy of the subclavian artery and its branches. Surg Gynecol Obstet, 108: 149

5. Hong JT, Park DK, Lee MJ, Kim SW, An HS (2008) Anatomical variations of the vertebral artery segment in the lower cervical spine: analysis by three-dimensional computed tomography angiography. Spine, 33: 2422-2426. doi: 10.1097/BRS.0b013e31818938d1.

6. Ionete C, Omojola MF (2006) MR angiographic demonstration of bilateral duplication of the extracranial vertebral artery: unusual course and review of the literature. Am J Neuroradiol, 27: 1304-1306.

7. Kemmetmüller H (1911) Über eine seltene Varietät der Art (Article in German). Vertebralis, Anat Embryol, 44: 305-360.

8. Kim DW (2009) Concomitant dual origin and fenestration of the left vertebral artery resembling dissection. J Korean Neurosurg Soc, 46: 498-500. doi: 10.3340/ jkns.2009.46.5.498.

9. Komiyama M, Morikawa T, Nakajima H, Nishikawa M, Yasui T (2001) High incidence of arterial dissection associated with left vertebral artery of aortic origin, Neurol Med Chir, 41: 8-12. doi: 10.2176/nmc.41.8.

10. Lazorthes G, Gouaze A, Zadeh JO, Jacques Santini J, Lazorthes Y, Burdin P (1971) Arterial vascularization of the spinal cord: recent studies of the anastomotic substitution pathways. J Neurosurg, 35: 253-262.

11. Moore KL, Persaud TVN (1988) The developing human: clinically oriented embryology (4 Ed.). Saunders. Philadelphia, PA, pp. 179-184.

12. Mordasisni P, Schmidt F, Schroth G, Remonda L (2008) Asymmetrical bilateral duplication of the extracranial vertebral arteries: report of a unique case. Eur J Radiol Extra, 67: e91-e94. doi:10.1016/j.ejrex.2008.05.016.

13. Nakamura M, Saga T, Tetsuka M, Watanabe $K$, Koga N, Takahashi N, Tabira Y, Takano Y, Chikasue T, Yamaki K (2012) A case of duplicated left vertebral artery and the research of the entrance of the vertebral artery in transverse foramen of cervical vertebra (Article in Japanese). Kurume igakukai zasshi, 75: 25-31.

14. Padget DH (1948) The development of the cranial arteries in the human embryo, Contr Embryol, 32: 205-261.

15. Padget DH (1954) Designation of the embryonic intersegmental arteries in reference to the vertebral artery and subclavian stem. Anat Rec, 119: 349-356.

16. Rameshbabu CS, Gupta OP, Gupta KK, Qasim M (2014) Bilateral asymmetrical duplicated origin of vertebral arteries: multidetector row CT angiographic study. Indian J Radiol Imaging, 24: 61-65. doi: 10.4103/0971-3026.130699.

17. Thomas AJ, Germanwala AV, Vora N, Prevedello DM, Jovin T, Kassam, A, Horowitz M (2008) Dual origin extracranial vertebral artery: case report and embryology, J Neuroimaging, 18: 173-176. doi: 10.1111/j.1552-6569.2007.00182.x.

18. Tobin WO, Killeen R, Kinsella JA, McCabe DJ (2010) Dual origin of the left vertebral artery: Extracranial MRA and CTA findings. J Neurol Sci, 298: 150-152. doi:10.1016/j. jns.2010.07.017.

19. Uchino A, Saito N, Takahashi M, Okada Y, Kozawa E, Nishi N, Mizukoshi W, Nakajima R, Watanabe Y (2013) Variations in the origin of the vertebral artery and its level of entry into the transverse foramen diagnosed by CT angiography. Neuroradiology, 55: 585-594. doi: 10.1007/ s00234-013-1142-0.

20. Yamaki KI, Saga T, Hirata T, Sakaino M, Nohno M, Kobayashi S, Hirao T (2006) Anatomical study of the vertebral artery in Japanese adults. Anat Sci Int, 81: 100-106. doi: 10.1111/j.1447-073X.2006.00133.x. 